Response to: 'On the approach for determining association between changes in marital quality and cardiovascular disease risk factors' by MM Pike

We thank Ms Pike ${ }^{1}$ for her interest in our study.

As is highlighted in the Discussion section of our paper, ${ }^{2}$ we agree that the exclusion of divorced men from our final analyses could have influenced the findings. This is one of many potential sources of bias that we identified in our discussion, including the exclusion of those whose marriages dissolved prior to or during the study, loss to follow-up bias due to participant attrition and the reduced likelihood that wives in poor quality relationships would have asked their partners to attend the follow-up clinic and hence would be missing.

We highlighted these differences in our comparison of baseline covariate data, finding that, 'as expected, men who were excluded from the analysis were more likely to be poorer, drink more alcohol and have worse marital quality.' As noted in our discussion, we believe that 'these biases would systematically attenuate any true relationship so that our observed findings may underestimate the true effect.' We would not seek to generalise our findings to divorced men as post-divorce risk factors may well change due to different life circumstances, so our findings are only generalisable to men who stay in a relationship whether they are happy or not.

Ms Pike notes that final analyses were restricted to those partners who were married and reported being the father of the child at all time points. As noted in our paper, this was due to our interest in comparisons of marital relationship quality over time (divorced partners would no longer have a relationship to quantify) and to ensure analyses were performed on the same study partners. This criteria led to the exclusion of 116 men from the final analysis. Ms Pike assumes that all 116 excluded men were divorced-rather than as specified a cohort that could not be both confirmed married and the father of the child at the second (T2) and third (T3) follow-up time points. At the third follow-up time point 
(T3), there were 44 divorced, 24 separated and 11 widowed men in the excluded sample, and 1 separated man in the included sample. This corresponds to a divorce rate of 17.6 per 1000, using the baseline sample (T1) as the appropriate denominator and not the T3 denominator. This is only 1.37 times greater, rather than 12 times greater than quoted background divorce rate of 12.9 per 1000 during the study period.

Ms Pike notes 'without baseline measurements of all of cardiovascular risk factors, it is not known whether the exposure groups differed significantly at baseline' which 'could be driving the significant findings of the study.' While we agree that it would have been preferable to present baseline cardiovascular risk data if these measures were available (we were able to do this for the change in BMI between T1 and T3), we would suggest that this is less of an issue than proposed. Our major aim is to test whether change in marital quality predicts differences in T3 outcomes. There is likely to be a weak to moderate (but not strong) correlation between these measures across 20 years. It is unclear why an individual's lipid or blood pressure would themselves determine change in marital quality other than through backdoor confounding by socioeconomic status which we have tried to account for in our multivariable models.

\section{TRANSPARENCY DECLARATION}

IB-B affirms that this manuscript is an honest, accurate and transparent account of the study being reported.

\section{Ian Bennett-Britton,, Alison Teyhan,, John Macleod,, Naveed Sattar, George Davey Smith,, Yoav Ben-Shlomo}

${ }^{1}$ Population Health Sciences, Bristol Medical School, University of Bristol, Bristol, UK

${ }^{2}$ Institute of Cardiovascular and Medical Sciences, University of Glasgow, Glasgow, UK

${ }^{3} \mathrm{MRC}$ Integrative Epidemiology Unit, University of Bristol, Bristol, UK

Correspondence to Dr lan Bennett-Britton, Population Health Sciences, Bristol Medical School, University of Bristol, Bristol BS8 2PS, UK; ian.bennettbritton@nhs.net
Correction notice This article has been corrected since it first published online. It has been made open access.

Acknowledgements We are extremely grateful to all the families who took part in this study, the midwives for their help in recruiting them and the whole Avon Longitudinal Study of Parents and Children (ALSPAC) team, which includes interviewers, computer and laboratory technicians, clerical workers, research scientists, volunteers, managers, receptionists and nurses.

Contributors For original referenced manuscript, IB-B co-conceived research question, cleaned data, co-wrote and performed statistical analysis, interpreted data, drafted and revised paper. IB-B drafted and revised response to letter to editor. He is guarantor. For original referenced manuscript, AT co-wrote statistical analysis plan, interpreted data, drafted and revised paper. AT, $J M, N S$ and GDS reviewed and approved response to letter to editor. For original referenced manuscript, $J M$ drafted, revised paper and is a co-director of the ALSPAC project. For original referenced manuscript, NS drafted and revised paper and was responsible for blood biomarker measurements used. For original referenced manuscript, GDS drafted, revised original paper and secured funding to maintain ALSPAC data collection and the resource. For original referenced manuscript, YB-S organised the data collection for the Focus on Fathers clinic, co-conceived original research question, co-wrote statistical analysis plan, supported the data analysis, drafted and revised paper. YB-S drafted, reviewed and approved response to letter to editor. This publication is the work of the authors and IB-B will serve as guarantor for the contents of this paper.

Funding The UK Medical Research Council and the Wellcome Trust (Grant ref: 102215/2/13/2) and the University of Bristol provide core support for ALSPAC. GDS works within the Medical Research Council Integrative Epidemiology Unit at the University of Bristol (MC_UU_12013/1). IB-B is an Academic Clinical Fellow in Primary Care funded by the National Institute of Health Research (ACF-2014-25-008). Funding bodies had no influence over the content of this manuscript.

Funding The UK Medical Research Council and the Wellcome Trust (Grant ref: 102215/2/13/2) and the University of Bristol provide core support for ALSPAC. GDS works within the Medical Research Council Integrative Epidemiology Unit at the University of Bristol (MC UU 12013/1). IB-B is an Academic Clinical Fellow in Primary Care funded by the National Institute of Health Research (ACF-2014-25-008). Funding bodies had no influence over the content of this manuscript.

Competing interests None declared.

Patient consent Not required.
Provenance and peer review Not commissioned: internally peer reviewed.

Data sharing statement A fully searchable Avon Longitudinal Study of Parents and Children (ALSPAC) data dictionary is available online. Sharing of ALSPAC data is encouraged and facilitated for all researchers from all disciplines across the world to maximise use of the resource. For more information on data applications, please see the ALSPAC website.

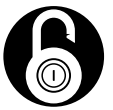

\section{OPEN ACCESS}

Open access This is an open access article distributed in accordance with the Creative Commons Attribution Non Commercial (CC BY-NC 4.0) license, which permits others to distribute, remix, adapt, build upon this work non-commercially, and license their derivative works on different terms, provided the original work is properly cited, appropriate credit is given, any changes made indicated, and the use is non-commercial. See: http:// creativecommons.org/licenses/by-nc/4.0/.

(c) Author(s) (or their employer(s)) 2018. Re-use permitted under CC BY-NC. No commercial re-use. See rights and permissions. Published by BMJ.

\section{Check for updates}

To cite Bennett-Britton I, Teyhan A, Macleod J, et al. J Epidemiol Community Health 2018;72:759-760.

Received 26 March 2018

Accepted 24 April 2018

Published Online First 30 May 2018

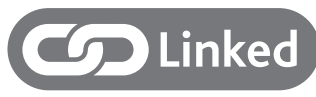

- http://dx.doi.org/10.1136/jech-2018-210445

J Epidemiol Community Health 2018;72:759-760. doi:10.1136/jech-2018-210797

\section{REFERENCES}

1 Pike MM. On the approach for determining association between changes in marital quality and cardiovascular disease risk factors. J Epidemiol Community Health 2018;72:760

2 Bennett-Britton I, Teyhan A, Macleod J, et al. Changes in marital quality over 6 years and its association with cardiovascular disease risk factors in men: findings from the ALSPAC prospective cohort study. J Epidemiol Community Health 2017;71:1094-100. 